\title{
EP-946 Coincidence of subarachnoidal hemorrhage and pituitary apoplexy
}

\author{
Gonca Oruk, Melda Apayadin, Husnu Yilmaz, Nurullah Yuceer, Baris Pamuk \\ Izmir Katip Celebi University Ataturk Training and Research Hospital, Izmir, Turkey
}

Pituitary apoplexy is a rare and life-threatening disorder often requiring emergency neurosurgical intervention to preserve vision and prevent cerebral herniation syndrome. Infarction or hemorrhage of an enlarged pituitary gland or pituitary tumor is the most common cause of pituitary apoplexy. Early recognition of this disorder is essential for preventing permanent visual loss or death; however, pituitary apoplexy often mimics subarachnoid hemorrhage, which in some cases may delay definitive diagnosis.

44 years old male patient was admitted to Emergency outpatient clinic with intense headache. He was discharged from the hospital after an administration of analgesic injection. But his mental status started to deteriorate at home and there were complaints of of blurring of vision with diplopia and drooping of the left eyelid. His headache was also persisting with same intensity. History of the patient revealed celiac disease. During second admission to the hospital, the patient was pale, pulse was $110 / \mathrm{min}$, and blood pressure recorded was $90 / 50 \mathrm{mmHg}$. On examination, ptosis was present on left side, periorbital swelling was also observed. Restriction of medial/upward movement of both eyes were present. Pupils were bilateral equal and normally reacting to light (Image 1).Visual acuity was 0.4 on right and 0.05 on the left side. The rest of the neurological examination and review of other systems were normal. Laboratory investigations were compatible with panhypopituitarism (Table 1). The patient was started on hydrocortisone and thyroid hormone replacement therapy. Magnetic resonance imaging (MRI) established diagnosis of pituitary apoplexy and subarachnoid hemorrhage

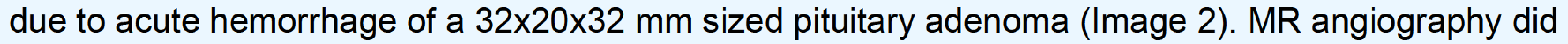
not establish an artery aneurysm. His status and hemorrhage recovered with the treatment given. $\mathrm{He}$ is going to be operated for the pituitary adenoma.

Image 1: Patient Image 2 : MR imaging (coronal)
Table 1: Laboratory evaluation
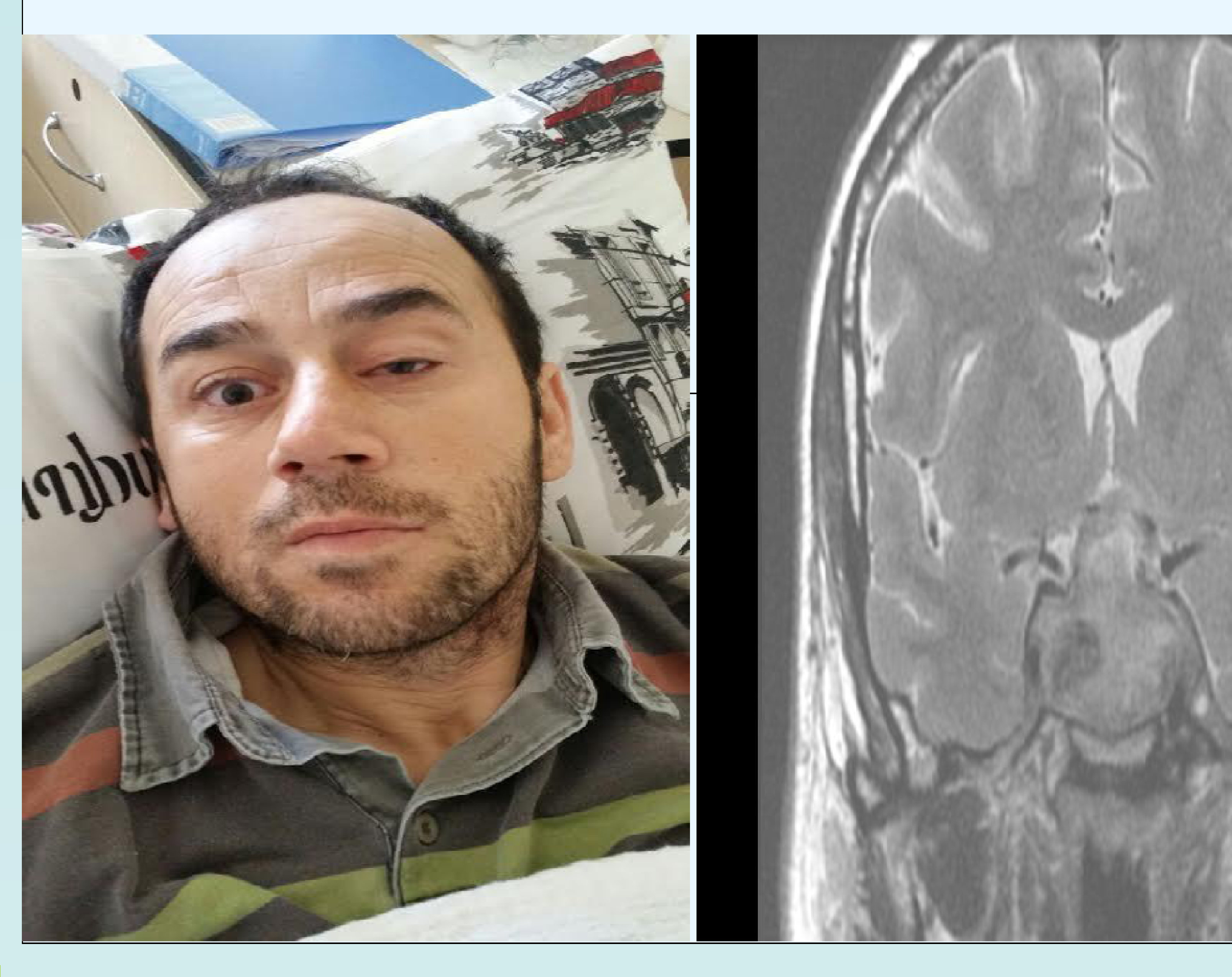

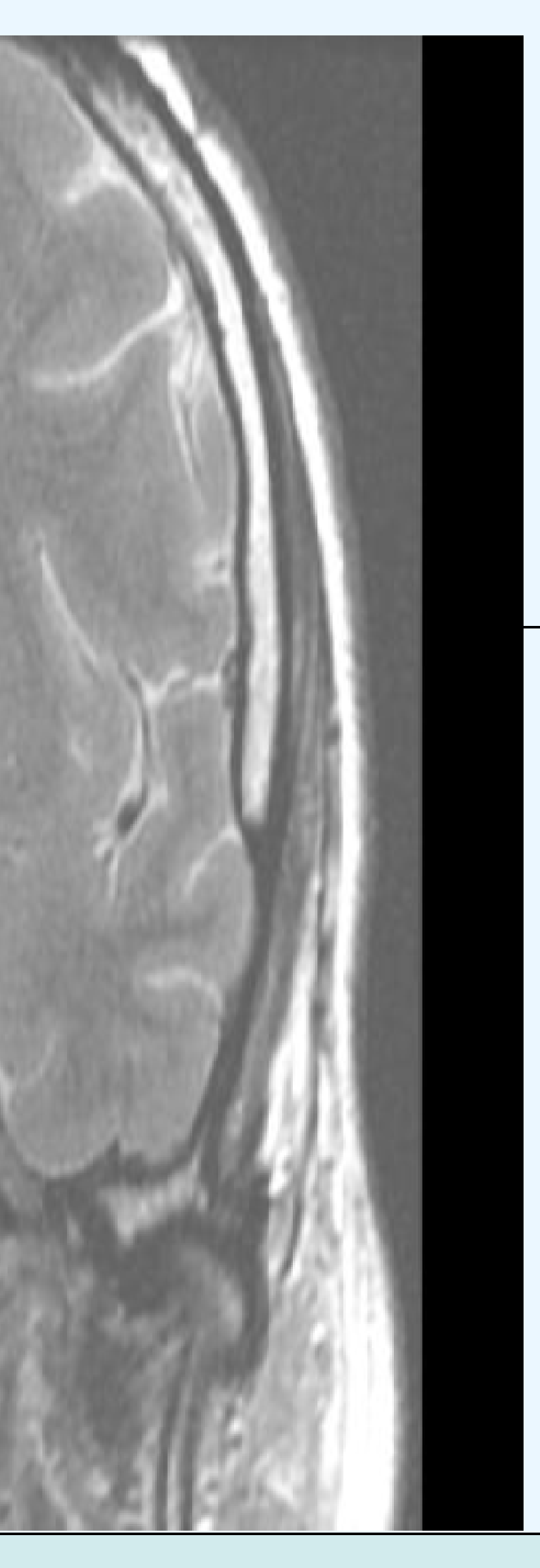

\begin{tabular}{|l|l|l|}
\hline TSH & $0.27 \mathrm{ulU} / \mathrm{mL}$ & $0.35-5.50$ \\
\hline FT3 & $0.68 \mathrm{pg} / \mathrm{mL}$ & $2.3-4.2$ \\
\hline FT4 & $0.45 \mathrm{ng} / \mathrm{dL}$ & $0.88-1.72$ \\
\hline CORTISOL & $2.5 \mathrm{ug} / \mathrm{dL}$ & $4.6-22.8$ \\
\hline & & \\
\hline FSH & $0.9 \mathrm{mIU} / \mathrm{mL}$ & $1.4-18.1$ \\
\hline LH & $0.2 \mathrm{mIU} / \mathrm{mL}$ & $1.5-9.3$ \\
\hline PROLACTIN & $0.7 \mathrm{ng} / \mathrm{mL}$ & $2.1-17.7$ \\
\hline GH & & \\
\hline
\end{tabular}

Multidisciplinary evaluation of these patients will determine diagnosis and the most appropriate emergency treatment plan and long-term management strategies. 